\title{
Novel Metabolically Stable PCA-1/ALKBH3 Inhibitor Has Potent Antiproliferative Effects on DU145 Cells In Vivo
}

\author{
MASAHIRO UEDA ${ }^{1,2}$, TADASHI SHIMIZU ${ }^{1,2}$, MIYUKI MABUCHI $^{1,2,3}$, KOTA HORIIKE $^{1,2}$, KAORI KITAE $^{4}$, \\ HIROAKI HASE ${ }^{4}$, YUKO UEDA $^{4}$, KAZUTAKE TSUJIKAWA $^{4 *}$ and AKITO TANAKA ${ }^{1,2,3 *}$ \\ ${ }^{1}$ Advanced Medical Research Center, and ${ }^{2}$ School of Pharmacy, Hyogo University of Health Sciences, Kobe, Japan; \\ ${ }^{3}$ KOBE Chemical Genetics, Ltd., Kobe, Japan; \\ ${ }^{4}$ Laboratory of Molecular and Cellular Physiology, Graduate School of Pharmaceutical Sciences, Suita, Japan
}

\begin{abstract}
Novel potent prostate cancer antigen-1 (PCA1)/alpha-ketoglutarate-dependent dioxygenase alkB homolog 3 (ALKBH3) inhibitors both in vivo and in vivo were designed and evaluated by a stability assay in an $\mathrm{S} 9$ mixture, a mixture of rat liver homogenate and co-factors, and oral absorbability assay in rat, as well as enzyme and cell assays, and resulted in the synthesis of a novel potent PCA-1/ALKBH3 inhibitor in vivo. Among them, compound $7 l$ exhibited potent inhibitory activities in a xenograft model bearing DU145 tumor at $10 \mathrm{mg} / \mathrm{kg}$ by subcutaneous administration without negative side-effects. This inhibitory activity in vivo was more potent than that of HUHSO15 at $32 \mathrm{mg} / \mathrm{kg}$, a known PCA-1/ALKBH3 inhibitor, or docetaxel at $2.5 \mathrm{mg} / \mathrm{kg}$, the drug clinically used for androgen-independent prostate cancer.
\end{abstract}

Developing novel drugs against prostate cancer that are effective against both androgen-dependent and independent cancer types is now urgently required (1). Tsujikawa et al. reported a novel gene that encodes a DNA and RNA-alkylating damage-repair enzyme called prostate cancer antigen (PCA)1/alpha-ketoglutarate-dependent dioxygenase alkB homolog 3 (ALKBH3) that is highly expressed in clinical prostate cancer cells; genetic inhibition by injecting siRNA in vivo effectively inhibited the growth of androgen-independent prostate cancer cells DU145 cells that also express high levels of PCA1/ALKBH3 (2-4). Suppression of PCA-1/ALKBH3 led to 3-

\footnotetext{
*These Authors contributed equally to this study.

Correspondence to: Akito Tanaka, School of Pharmacy, Hyogo University of Health Sciences, 1-3-6 Minatojima, Chuo-ku, Kobe, 650-8530. Japan. Tel: +81 783043025, Fax: +81 783042767, e-mail: tanaka-a@huhs.ac.jp
}

Key Words: Anti-prostate cancer drug, docetaxel, DU145, xenograft model, anticancer drug, metabolic reaction, hepatic microsome, S9 mixture, drug design. methylcytosine accumulation and reduced cell proliferation in various cell lines (5). Therefore, a small and orally available PCA-1/ALKBH3 inhibitor could be a novel and clinically effective anti-prostate cancer drug, even for hormoneindependent cancer. In previous work, we reported the first PCA-1/ALKBH3 inhibitor, HUHS015 (Figure 1), and its effectiveness in a xenograft model bearing DU145 tumors without any observable side-effects or toxicity. However, the inhibitory activity of HUHS015 was not sufficient especially after 1 week, although subcutaneous injection of $32 \mathrm{mg} / \mathrm{kg}$ HUHS015 completely suppressed the growth of DU145 cells in xenograft model up to 1 week (Figure 2) (6). Interestingly, in continuous study using rat $\mathrm{S} 9$ mixture, a mixture of rat liver homogenate including many metabolic enzymes and co-factors that is often used to estimate a compound's metabolic stability, we found that no HUHS015 was not detected in a S9 mixture at $37^{\circ} \mathrm{C}$ after a 10 -min treatment and only $42 \%$ of HUHS 015 remained even at $15^{\circ} \mathrm{C}$ indicating that HUHSO15 was easily decomposed in liver in vivo after administration. In fact, only $0.08 \mu \mathrm{g} / \mathrm{ml}$ of HUHS015 was found in rat serum $60 \mathrm{~min}$ after oral administration of $32 \mathrm{mg} / \mathrm{kg}$, while no metabolite so far has been identified, and its suppressory effects in vivo were not adequate in a xenograft model after long-term administration (Figure 2). Accordingly, we next focused our efforts to obtain novel PCA-1/ALKBH3 inhibitors that were more stable and effective in in vivo assays during the administration period. We herein report the design of novel PCA-1/ALKBH3 inhibitor and in vitro as well as in vivo structure-activity relationship studies, stability assay in S9 mixture, oral absorbability assays in rat, as well as enzyme and cell assays.

\section{Materials and Methods}

Cell culture. The human prostate cancer cell line DU145 was supplied from the Cell Resource Center for Biomedical Research Institute of Development, Aging, and Cancer, Tohoku University, Japan. The cell line was maintained in Dulbecco's modified Eagle's medium (DMEM) supplemented with $10 \%$ fetal calf serum (FCS) and $100 \mu \mathrm{g} / \mathrm{ml}$ kanamycin at $37^{\circ} \mathrm{C}$ under a humidified atmosphere containing $5 \% \mathrm{CO}_{2}$. 


\section{Optimization of $\mathbf{R}^{1}, \mathbf{R}^{2}$, and $\mathbf{R}^{3}$}

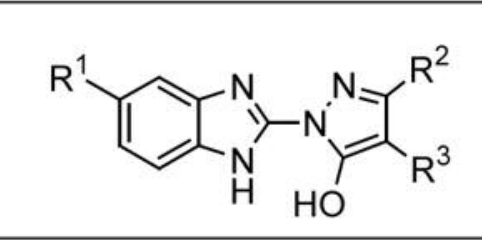<smiles>Cc1ccc2[nH]c(-n3nc(C)c(Cc4ccccc4)c3O)nc2c1</smiles>

HUHS015 (1)<smiles>Cc1nn(-c2nc3cc(F)ccc3[nH]2)c(O)c1-c1ccccc1</smiles>

Compound 7I

Figure 1. Structure of inhibitors studied.

A

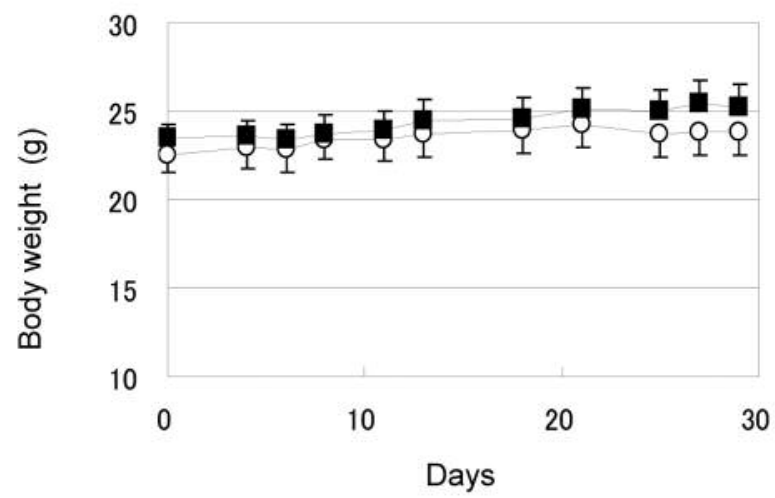

B

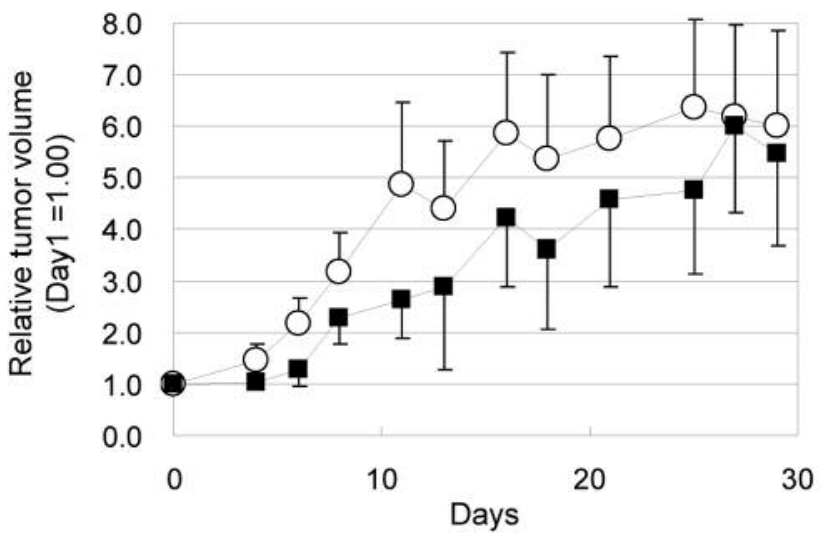

Figure 2. The body weights and anti-proliferative effects of HUHSO15 in mice bearing DU145 cell xenografts. Male nude mice were implanted subcutaneously with approximately $8 \times 10^{6}$ DU145 cells mixed with Matrige ${ }^{T M}$ into the right flank. When the estimated tumor volume had reached almost $200 \mathrm{~mm}^{3}$, after randomization, mice were treated with HUHSO15 subcutaneously administered once a day at $32 \mathrm{mg} / \mathrm{kg}$ (open symbols) or with vehicle alone (closed symbols). A: Body weights were measured at intervals. B: Tumor volume was calculated by caliper measurements of the width $(W)$ and length $(L)$ (volume $\left.=L \times W^{2} / 2\right)$, and tumor volumes were estimated relative to those at day 0 . Each value represents the mean $\pm S E$ of six mice. No statistically significant differences were observed by Student's t-test.

Animal care. Male nude BALB/c mice and male Sprague-Dawley (SD) rats were purchased from Japan SLC Inc. (Shizuoka, Japan) at 4 or 6 weeks old, almost 13 or $200 \mathrm{~g}$ body weight. Animals were kept under conditions of constant temperature and humidity, and fed a standard diet and water ad libitum. All animal experiments in this study were approved by our Institutional Animal Care Committee (\#2013-01, 2013-19, 2015-28, and 2015-29).

Synthesis of compounds studied in this study. The substituted pyrazoles studied in this work were synthesized by condensing substituted hydrazines (5) with $\beta$-keto esters (6) as shown in Figure 3. Hydrazine derivatives (5) were synthesized from ophenylenediamines (2) via 1,3-dihydro-benzimidazol-2-ones (3) and 2-chloro-benzimidazoles (4). ${ }^{1} \mathrm{H}$-NMR spectra were recorded on a JEOL JNM-ECX400 spectrometer at $400 \mathrm{MHz}$, or Agilent NMR system PS 600 system at $600 \mathrm{MHz}$ using $\mathrm{CDCl}_{3}$, dimethylsulfoxide (DMSO) $-\mathrm{d}_{6}, \mathrm{CD}_{3} \mathrm{OD}$ or acetone- $\mathrm{d}_{6}$ as solvent. Chemical shifts were given in $\delta$ values $(\mathrm{ppm})$, using tetramethylsilane $(\delta=0.00)$ as the internal standard; coupling constants $(J)$ were given in Hz. Signal multiplicities were characterized as s (singlet), d (doublet), t (triplet), q (quartet), m (multiplet), br (broad signal). IR spectra were recorded on a JEOL FT-IR 4100 spectrometer. ESI-MS spectra were taken on Bruker microTOF-Q mass spectrometer. All reactions were monitored by thin-layer chromatography carried out on a $0.25 \mathrm{~mm}$ E. Merck silica gel plates $60 \mathrm{~F}_{254}$ using UV light, iodine, or $5 \%$ ethanolic phosphomolybdic acid solution and heat as developing agents. 


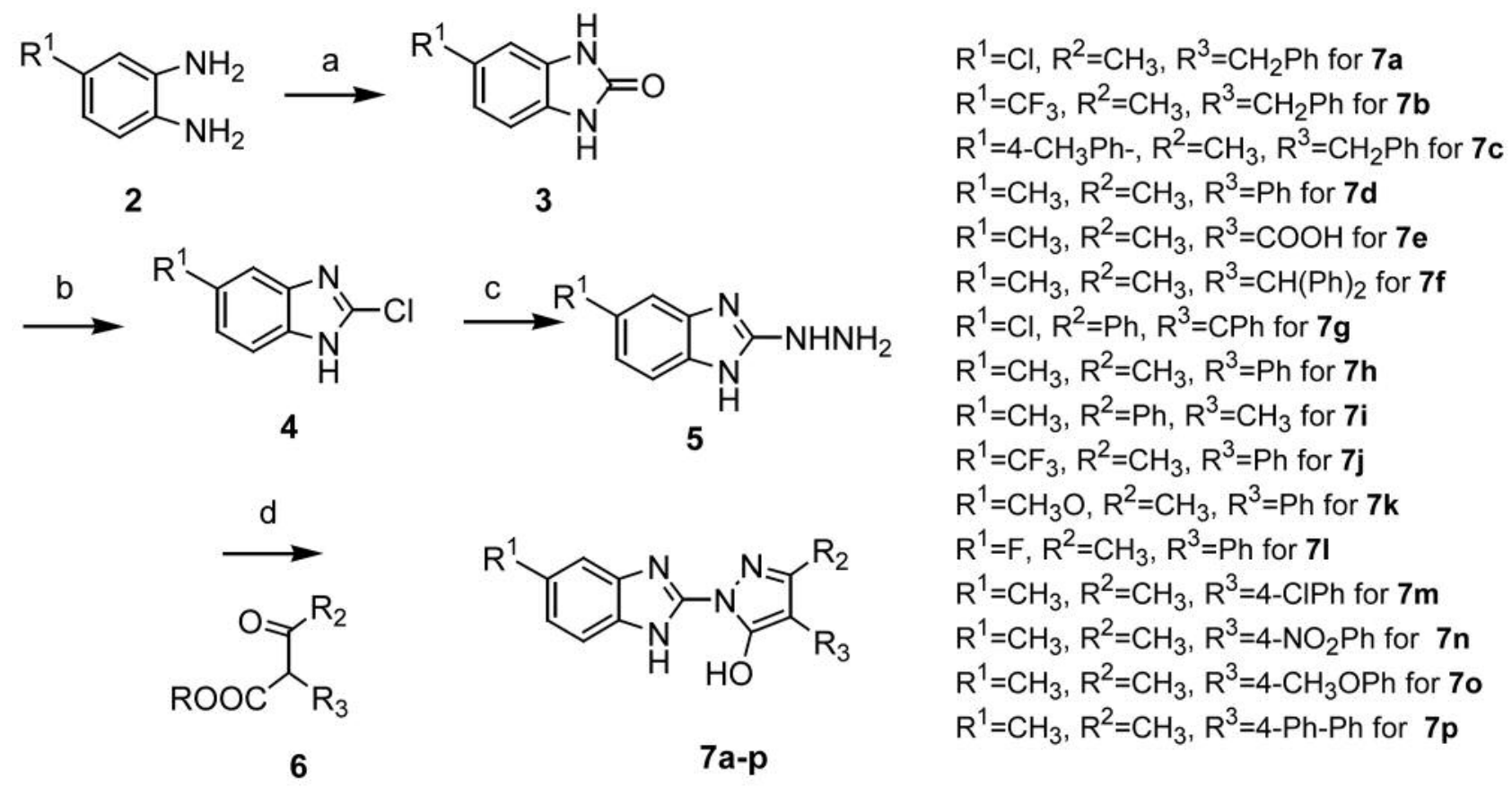

Figure 3. Scheme for synthesis of compounds studied in this work. Reagents and conditions: (a) 1,1-carbonyldiimidazole, (b) $\mathrm{POCl}_{3}$, (c) $\mathrm{NH}_{2} \mathrm{NH}_{2}$ hydrate, (d) 6, in $\mathrm{AcOH}$.

Synthesis of 5-fluoro-1H-benzo[d]imidazol-2(3H)-one (3l). To a solution of 4-fluorobenzene-1, 2-diamine $\left(2 \mathrm{l}, \mathrm{R}^{1}=\mathrm{F}, 5.20 \mathrm{~g}, 41.2\right.$ $\mathrm{mmol})$ in THF $(50 \mathrm{ml})$ were added 1,1-carbonyldiimidazole $(7.35 \mathrm{~g}$, $45.4 \mathrm{mmol}$ ) in 5 parts under ice-cooling. After being stirred for $2 \mathrm{~h}$ at room temperature, the reaction mixture was added to $1 \mathrm{~N} \mathrm{HCl}$ under ice-cooling. The reaction mixture was filtered and dried under reduced pressure to give 5-fluoro- $1 H$-benzo[d]imidazol-2( $3 H)$-one (31, $\mathrm{R}^{1}=\mathrm{F}, 5.20 \mathrm{~g}$ ), was used without further purification. 1H-NMR $\left(400 \mathrm{MHz}, \mathrm{DMSO}-d_{6}\right) \delta 6.73\left(1 \mathrm{H}, \mathrm{ddd}, \mathrm{J}=10.4\left(J_{\mathrm{HF}}\right), 8.4\right.$ and $\left.2.4 \mathrm{~Hz}\right)$, $6.76\left(1 \mathrm{H}, \mathrm{dd}, \mathrm{J}=9.2\left(J_{\mathrm{HF}}\right)\right.$, and $\left.2.4 \mathrm{~Hz}\right), 6.87(1 \mathrm{H}, \mathrm{dd}, \mathrm{J}=8.4$ and 4.8 $\left.\left(J_{\mathrm{HF}}\right) \mathrm{Hz}\right), 10.6(1 \mathrm{H}, \mathrm{s}), 10.7(1 \mathrm{H}, \mathrm{s})$.

Synthesis of 5-fluoro-2-hydrazino-1H-benzo[d]imidazole (5l). A mixture of 5 -fluoro-1H-benzo[d]imidazol-2(3H)-one $\left(3 \mathrm{l}, \mathrm{R}^{1}=\mathrm{F}\right.$, $5.20 \mathrm{~g}$ ) and phosphoryl chloride $(32 \mathrm{ml}, 341 \mathrm{mmol}$ ) was stirred for $24 \mathrm{~h}$ at $120^{\circ} \mathrm{C}$. After cooling to ambient temperature, the mixture was added to $1 \mathrm{~N} \mathrm{NaOH}$ (resulting $\mathrm{pH}$ was almost 8 ). The aqueous layer was extracted with ethyl acetate for three times. The combined organic layers were washed with water and brine, then dried over anhydrous $\mathrm{MgSO}_{4}$, filtered and concentrated under reduced pressure. The crude product was purified by silica gel column chromatography ( $n$-hexane/ethyl acetate $=1 / 1)$ to give compound $4 \mathrm{I}\left(\mathrm{R}^{1}=\mathrm{F}, 4.22 \mathrm{~g}\right.$, $60 \%$ by 2 steps) as pale yellow precipitates. $\left(400 \mathrm{MHz}, \mathrm{DMSO}-\mathrm{d}_{6}\right)$ $\delta 7.09\left(1 \mathrm{H}\right.$, ddd, $J=9.2\left(J_{\mathrm{HF}}\right), 8.8$ and $\left.2.8 \mathrm{~Hz}\right), 7.36(1 \mathrm{H}, \mathrm{dd}, J=9.2$ $\left(J_{\mathrm{HF}}\right)$, and $\left.2.8 \mathrm{~Hz}\right), 7.52\left(1 \mathrm{H}, \mathrm{dd}, J=8.8\right.$ and $\left.4.8\left(J_{\mathrm{HF}}\right) \mathrm{Hz}\right)$; IR $(\mathrm{KBr})$ : $3035,2959,2900.2784,2636,1440.1348,1148,1108 \mathrm{~cm}^{-1}$; ESIHRMS (positive ion, sodium formate): calcd for $\mathrm{C}_{7} \mathrm{H}_{3} \mathrm{ClFN}_{2}$ ([M$\left.\mathrm{H}]^{-}\right)$168.9974; found 168.9986 ; m.p. $146-149^{\circ} \mathrm{C}$. A mixture of $4 \mathrm{l}$ $(1.30 \mathrm{~g}, 7.62 \mathrm{mmol})$ and hydrazine monohydrate $(7.30 \mathrm{ml}, 152$ $\mathrm{mmol}$ ) was stirred for $2.5 \mathrm{~h}$ at $120^{\circ} \mathrm{C}$. After being cooled to ambient temperature, the reaction mixture was added to water. $\mathrm{NaCl}$ was added to the mixture and stirred at ambient temperature, the resulting precipitates were collected by filtration. The precipitates were washed with water, and then dried in vacuo to give 5-fluoro-2hydrazino-1H-benzo[d]imidazole $\left(\mathbf{5 l}, \mathrm{R}^{1}=\mathrm{F}, 720 \mathrm{mg}, 56 \%\right)$ as white solid. ${ }^{1} \mathrm{H}-\mathrm{NMR}\left(400 \mathrm{MHz}, \mathrm{DMSO}-\mathrm{d}_{6}\right) \delta 4.46(2 \mathrm{H}, \mathrm{br} \mathrm{s}), 6.63(1 \mathrm{H}$, broad), $6.87\left(1 \mathrm{H}, \mathrm{dd}, J=10.0\left(J_{\mathrm{HF}}\right)\right.$ and $\left.1.6 \mathrm{~Hz}\right), 7.05(1 \mathrm{H}, \mathrm{dd}, J=8.0$ and $\left.4.4\left(J_{\mathrm{HF}}\right) \mathrm{Hz}\right), 7.89(1 \mathrm{H}$, broad $), 11.0(1 \mathrm{H}$, broad $): 3318,3272$, 3025, 2786, 1672, 1563, 1480. 1445, 1409, 1293, 1243, 1213, 1148, $1009 \mathrm{~cm}^{-1}$; ESI-HRMS (positive ion, sodium formate): calcd for $\mathrm{C}_{7} \mathrm{H}_{6} \mathrm{FN}_{4}\left([\mathrm{M}-\mathrm{H}]^{-}\right)$165.0581; found 165.0597; m.p.189-193.

Synthesis of 1-(5-fluoro-1H-benzimidazol-2-yl)-3-methyl-4-phenyl$1 \mathrm{H}$ - pyrazol-5-ol (7l). A mixture of 51 (700 mg, $4.21 \mathrm{mmol})$ and ethyl 3-oxo-2-phenylbutanoate $(\mathbf{6 1}, 928 \mathrm{mg}, 4.21 \mathrm{mmol})$ in acetic acid $(7 \mathrm{ml})$ was stirred for $12 \mathrm{~h}$ at ambient temperature. The reaction mixture was poured into water $(30 \mathrm{ml})$ and stirred at ambient temperatures. The resulting precipitates were collected by filtration, and washed water and then with $50 \% \mathrm{EtOH}$ to afford (71, $880 \mathrm{mg}$, $68 \%$ ). The other compounds studied in this work were prepared in a similar manner, and their analytical data are provided in Table I.

PCA-1-inhibitory activity. An assay system for PCA-1 demethylase inhibitors has been described in full elsewhere (6). Briefly, $4 \mathrm{ng}$ of PCA-1 with or without investigatory compounds was incubated with 80 fmol 3-methyl cytosine oligo DNA (100 b.p.) (GeneDesign, Inc., Ibaraki, Osaka, Japan) as a substrate to be demethylated in buffer [50 mM Tris- $\mathrm{HCl}$ (pH 8.0), $2 \mathrm{mM}$ ascorbic acid, $100 \mu \mathrm{M}$ oxoglutarate, and $40 \mu \mathrm{M}$ ferrous sulfate] and incubated at $37^{\circ} \mathrm{C}$ for $1 \mathrm{~h}$. The reaction was stopped by dilution to 20 times volume by 
Table I. Analytical data of HUHSO15 (1) and evaluated compounds (7a-7p).

\begin{tabular}{|c|c|c|c|c|}
\hline Compound & ${ }^{1} \mathrm{H}$-NMR, $\delta$ values $*$ & IR (KBr) & ESI-HRMS & $\begin{array}{l}\text { Melting point } \\
\left({ }^{\circ} \mathrm{C}\right)\end{array}$ \\
\hline 1 & $\begin{array}{l}\text { DMSO: } 2.15(3 \mathrm{H}, \mathrm{s}), 2.39(3 \mathrm{H}, \mathrm{s}), 3.59(2 \mathrm{H}, \mathrm{s}) \\
6.96-7.00(1 \mathrm{H}, \mathrm{m}), 7.13-7.20(1 \mathrm{H}, \mathrm{m}), 7.23-7.29 \\
(4 \mathrm{H}, \mathrm{m}), 7.31(1 \mathrm{H}, \mathrm{br} s), 7.39(1 \mathrm{H}, \mathrm{d}, J=8.2 \mathrm{~Hz})\end{array}$ & $\begin{array}{l}3312,3024,2936,2915, \mathrm{Ca} \\
1653,1553 \mathrm{~cm}^{-1}\end{array}$ & $\begin{array}{l}\text { Calcd for } \mathrm{C}_{19} \mathrm{H}_{19} \mathrm{~N}_{4} \mathrm{O}\left([\mathrm{M}+\mathrm{H}]^{+}\right) \\
319.1559 ; \text { found } 319.1588\end{array}$ & $198-200$ \\
\hline $7 a$ & $\begin{array}{l}\text { DMSO: } 2.17(3 \mathrm{H}, \mathrm{s}), 3.59(2 \mathrm{H}, \mathrm{s}), 7.13-7.21(2 \mathrm{H}, \mathrm{m}) \text {, } \\
7.24-7.30(4 \mathrm{H}, \mathrm{m}), 7.52(1 \mathrm{H}, \mathrm{d}, J=8.7 \mathrm{~Hz}), \\
7.55(1 \mathrm{H}, \mathrm{d}, J=2.3 \mathrm{~Hz})\end{array}$ & $\begin{array}{l}3263,3031,2914,2842 \\
1654,1623,1556 \mathrm{~cm}^{-1}\end{array}$ & $\begin{array}{l}\text { Calcd for } \mathrm{C}_{18} \mathrm{H}_{16} \mathrm{ClN}_{4} \mathrm{O} \\
\quad\left([\mathrm{M}+\mathrm{H}]^{+}\right) 339.1007 \\
\quad \text { found } 339.0978\end{array}$ & $101-104$ \\
\hline $7 b$ & $\begin{array}{l}\text { DMSO: } 2.19(3 \mathrm{H}, \mathrm{s}), 3.60(2 \mathrm{H}, \mathrm{s}), 7.14-7.21(1 \mathrm{H}, \mathrm{m}), \\
7.24-7.31(4 \mathrm{H}, \mathrm{m}), 7.46-7.52(1 \mathrm{H}, \mathrm{m}), \\
7.70(1 \mathrm{H}, \mathrm{d}, J=8.2 \mathrm{~Hz}), 7.84(1 \mathrm{H}, \mathrm{s})\end{array}$ & $\begin{array}{l}3033,2935,2901 \\
1637,1551 \mathrm{~cm}^{-1}\end{array}$ & $\begin{array}{l}\text { Calcd for } \mathrm{C}_{19} \mathrm{H}_{16} \mathrm{~F}_{3} \mathrm{~N}_{4} \mathrm{O} \\
\quad\left([\mathrm{M}+\mathrm{H}]^{+}\right) 373.1271 \\
\quad \text { found } 373.1259\end{array}$ & $216-218$ \\
\hline $7 \mathrm{c}$ & $\begin{array}{l}\text { DMSO: } 2.17(3 \mathrm{H}, \mathrm{s}), 2.35(3 \mathrm{H}, \mathrm{s}), 3.60(2 \mathrm{H}, \mathrm{s}), \\
7.13-7.21(1 \mathrm{H}, \mathrm{m}), 7.23-7.31(6 \mathrm{H}, \mathrm{m}), 7.43(1 \mathrm{H}, \mathrm{dd}, \\
J=1.8,8.2 \mathrm{~Hz}), 7.51-7.59(3 \mathrm{H}, \mathrm{m}), 7.72(1 \mathrm{H}, \mathrm{br} \mathrm{s})\end{array}$ & $\begin{array}{c}3446,3027,2962,2873 \\
1632,1556 \mathrm{~cm}^{-1}\end{array}$ & $\begin{array}{l}\text { Calcd for } \mathrm{C}_{25} \mathrm{H}_{23} \mathrm{~N}_{4} \mathrm{O} \\
\left([\mathrm{M}+\mathrm{H}]^{+}\right) 395.1866 \\
\text { found } 395.1852\end{array}$ & $120-124$ \\
\hline 7d & $\begin{array}{l}\text { DMSO: } 2.39(3 \mathrm{H}, \mathrm{s}), 2.41(3 \mathrm{H}, \mathrm{s}), 7.07(1 \mathrm{H}, \mathrm{dd}, J=0.9 \\
\text { and } 8.2 \mathrm{~Hz}), 7.12-7.17(1 \mathrm{H}, \mathrm{m}), 7.32-7.38(3 \mathrm{H}, \mathrm{m}), 7.44 \\
(1 \mathrm{H}, \mathrm{d}, J=8.2 \mathrm{~Hz}), 7.64-7.69(2 \mathrm{H}, \mathrm{m})\end{array}$ & $\begin{array}{l}3060.1660 .1596 \\
1514 \mathrm{~cm}^{-1}\end{array}$ & $\begin{array}{l}\text { Calcd for } \mathrm{C}_{18} \mathrm{H}_{17} \mathrm{~N}_{4} \mathrm{O} \\
\left([\mathrm{M}+\mathrm{H}]^{+}\right) 305.1397 \\
\text { found } 305.1402\end{array}$ & $130-134$ \\
\hline $7 e$ & $\begin{array}{l}\text { DMSO: } 2.14(3 \mathrm{H}, \mathrm{s}), 2.38(3 \mathrm{H}, \mathrm{s}), 3.21(2 \mathrm{H}, \mathrm{s}), 6.98 \\
(1 \mathrm{H}, \mathrm{d}, J=7.5 \mathrm{~Hz}), 7.31(1 \mathrm{H}, \mathrm{s}), 7.39(1 \mathrm{H}, \mathrm{d}, J=7.5 \mathrm{~Hz})\end{array}$ & $\begin{array}{l}3175,3034,1679 \\
1651,1635,1605 \\
1559,1507 \mathrm{~cm}^{-1}\end{array}$ & $\begin{array}{l}\text { Calcd for } \mathrm{C}_{14} \mathrm{H}_{13} \mathrm{~N}_{4} \mathrm{O}_{3} \\
\left.\text { ([M-H }]^{-}\right) 285.0993 \\
\quad \text { found } 285.0983\end{array}$ & $246-248$ \\
\hline $7 f$ & $\begin{array}{l}\text { DMSO: } 2.08(3 \mathrm{H}, \mathrm{s}), 5.28(1 \mathrm{H}, \mathrm{s}), 7.13-7.24(4 \mathrm{H}, \mathrm{m}) \text {, } \\
\text { 7.26-7.33 }(8 \mathrm{H}, \mathrm{m}), 7.48-7.53(2 \mathrm{H}, \mathrm{m})\end{array}$ & $\begin{array}{l}3229,3025,1656 \\
1559 \mathrm{~cm}^{-1}\end{array}$ & $\begin{array}{l}\text { Calcd for } \mathrm{C}_{24} \mathrm{H}_{21} \mathrm{~N}_{4} \mathrm{O} \\
\left([\mathrm{M}+\mathrm{H}]^{+}\right) 381.1710 \\
\text { found } 381.1707\end{array}$ & $165-167$ \\
\hline $7 \mathrm{~g}$ & $\begin{array}{l}\text { DMSO: } 7.14(1 \mathrm{H}, \mathrm{t}, J=7.3 \mathrm{~Hz}), 7.20-7.30(3 \mathrm{H}, \mathrm{m}) \\
7.33(2 \mathrm{H}, \mathrm{d}, J=7.3 \mathrm{~Hz}), 7.37-7.45(3 \mathrm{H}, \mathrm{m}), 7.45-7.55 \\
(2 \mathrm{H}, \mathrm{m}), 7.58(1 \mathrm{H}, \mathrm{d}, J=8.7 \mathrm{~Hz}), 7.62(1 \mathrm{H}, \mathrm{br} \mathrm{s})\end{array}$ & $\begin{array}{l}3101,3073,3059,1651 \\
1596,1572,1555 \\
1510.1466 \mathrm{~cm}^{-1}\end{array}$ & $\begin{array}{l}\text { Calcd for } \mathrm{C}_{22} \mathrm{H}_{14} \mathrm{ClN}_{4} \mathrm{O} \\
\quad\left([\mathrm{M}-\mathrm{H}]^{-}\right) 385.0856 \\
\text { found } 385.0870\end{array}$ & $111-117$ \\
\hline $7 \mathrm{~h}$ & $\begin{array}{l}\text { CDCl3: } 2.39(3 \mathrm{H}, \mathrm{s}), 7.04(2 \mathrm{H}, \mathrm{d}, J=7.8 \mathrm{~Hz}) \\
7.05-7.50(12 \mathrm{H}, \mathrm{m})\end{array}$ & $\begin{array}{l}3419,3059,2974,1641 \\
1615,1600,1565 \\
1513,1469 \mathrm{~cm}^{-1}\end{array}$ & $\begin{array}{l}\text { Calcd for } \mathrm{C}_{23} \mathrm{H}_{17} \mathrm{~N}_{4} \mathrm{O} \\
\left.\text { ([M-H }]^{-}\right) 365.1402 \\
\quad \text { found } 365.1416\end{array}$ & Decomp. \\
\hline $7 \mathbf{i}$ & $\begin{array}{l}\text { CDCl3: } 2.00(3 \mathrm{H}, \mathrm{s}), 2.44(3 \mathrm{H}, \text { br s }), 7.06(1 \mathrm{H}, \mathrm{br} \mathrm{s}), \\
7.15-7.50(7 \mathrm{H}, \mathrm{m}), 8.43(2 \mathrm{H}, \mathrm{br} \mathrm{s})\end{array}$ & $\begin{array}{c}3173,3026,2923,1662 \\
1652,1634,1617,1558 \\
1508,1473 \mathrm{~cm}^{-1}\end{array}$ & $\begin{array}{l}\text { Calcd for } \mathrm{C}_{18} \mathrm{H}_{15} \mathrm{~N}_{4} \mathrm{O} \\
\left([\mathrm{M}-\mathrm{H}]^{-}\right) 303.1246 \\
\text { found } 303.1269\end{array}$ & $118-123$ \\
\hline $7 \mathbf{j}$ & $\begin{array}{l}\text { CDCl3: } 2.37(3 \mathrm{H}, \mathrm{s}), 7.32(1 \mathrm{H}, \mathrm{t}, J=7.2 \mathrm{~Hz}) \\
\text { 7.40-7.50 }(2 \mathrm{H}, \text { broad }), 7.45(\mathrm{H}, \mathrm{t}, J=7.2 \mathrm{~Hz}) \\
7.61(2 \mathrm{H}, \mathrm{d}, J=7.2 \mathrm{~Hz}), 7.60-7.78(1 \mathrm{H}, \text { broad }) .\end{array}$ & $\begin{array}{l}3435,2922,2854,1637 \\
1553,1437,1399,1329,1250 \\
1220,1164,1051 \mathrm{~cm}^{-1}\end{array}$ & $\begin{array}{c}\text { Calcd for } \mathrm{C}_{18} \mathrm{H}_{12} \mathrm{~F}_{3} \mathrm{~N}_{4} \mathrm{O} \\
\left([\mathrm{M}-\mathrm{H}]^{-}\right) 357.0969 ; \\
\text { found } 357.0977 .\end{array}$ & $117-120$ \\
\hline $7 \mathbf{k}$ & $\begin{array}{l}\mathrm{CDCl} 3: 2.35(3 \mathrm{H}, \mathrm{s}), 3.66(3 \mathrm{H}, \mathrm{s}), 6.81(1 \mathrm{H}, \mathrm{dd} \\
J=9.0 \text { and } 2.4 \mathrm{~Hz}), 6.80-6.93(1 \mathrm{H}, \text { broad }), 7.15-7.30 \\
(1 \mathrm{H}, \text { broad }), 7.26(1 \mathrm{H}, \mathrm{t}, J=7.2 \mathrm{~Hz}), 7.41(2 \mathrm{H}, \mathrm{t} \\
J=7.2 \mathrm{~Hz}), 7.67(2 \mathrm{H}, \mathrm{d}, J=7.2 \mathrm{~Hz}) .\end{array}$ & $\begin{array}{c}3464,3055,2948,2832 \\
1656,1597,1551,1512 \\
1435,1401,1367,1317,1278 \\
1197,1157,1073,1027 \mathrm{~cm}^{-1}\end{array}$ & $\begin{array}{c}\text { Calcd for } \mathrm{C}_{18} \mathrm{H}_{16} \mathrm{~N}_{4} \mathrm{O}_{2} \\
\left([\mathrm{M}+\mathrm{H}]^{+}\right) 321.1346 \\
\text { found } 321.1336\end{array}$ & $127-132$ \\
\hline 71 & $\begin{array}{l}\text { DMSO: } 2.40(3 \mathrm{H}, \mathrm{s}), 7.65(1 \mathrm{H}, \mathrm{ddd}, J=9.0(\mathrm{H}-\mathrm{F}), \\
8.4 \text { and } 2.0 \mathrm{~Hz}), 7.21(1 \mathrm{H}, \mathrm{t}, J=8.4 \mathrm{~Hz}), 7.35(1 \mathrm{H}, \\
\mathrm{dd}, J=9.0(\mathrm{H}-\mathrm{F}) \text { and } 2.0 \mathrm{~Hz}), 7.40(2 \mathrm{H}, \mathrm{t}, J=8.4 \mathrm{~Hz}), \\
7.54(1 \mathrm{H}, \mathrm{dd}, J=8.4 \text { and } 4.8(\mathrm{H}-\mathrm{F}) \mathrm{Hz}) \\
7.65(2 \mathrm{H}, \mathrm{d}, J=8.4 \mathrm{~Hz})\end{array}$ & $\begin{array}{c}3463,3066,2922,2857,1665 \\
1556,1512,1491,1432,1374 \\
1307,1272,1247,1137 \\
1105,1007 \mathrm{~cm}^{-1}\end{array}$ & $\begin{array}{l}5, \text { Calcd for } \mathrm{C}_{17} \mathrm{H}_{13} \mathrm{FN}_{4} \mathrm{ONa} \\
\quad\left([\mathrm{M}+\mathrm{Na}]^{+}\right) 331.0966 \\
\quad \text { found } 331.0968\end{array}$ & $115-119$ \\
\hline $7 \mathrm{~m}$ & $\begin{array}{l}\text { DMSO: } 2.38(3 \mathrm{H}, \mathrm{s}), 2.41(3 \mathrm{H}, \mathrm{s}), 7.10(1 \mathrm{H}, \mathrm{dd}, \\
J=8.4 \text { and } 1.8 \mathrm{~Hz}), 7.36(1 \mathrm{H}, \mathrm{d}, J=1.8 \mathrm{~Hz}) \\
7.36(2 \mathrm{H}, \mathrm{d}, J=8.4 \mathrm{~Hz}), 7.45(1 \mathrm{H}, \mathrm{d}, J=8.4 \mathrm{~Hz}), \\
7.73(2 \mathrm{H}, \mathrm{d}, J=8.4 \mathrm{~Hz}) .\end{array}$ & $\begin{array}{c}3029,2954,2903,1669,1638 \\
1591,1513,1434,1396,1229 \\
1206,1182,1132,1093 \mathrm{~cm}^{-1}\end{array}$ & $\begin{array}{c}8, \quad \text { Calcd for } \mathrm{C}_{18} \mathrm{H}_{14} \mathrm{ClN}_{4} \mathrm{O} \\
9, \quad\left([\mathrm{M}-\mathrm{H}]^{-}\right) 337.0862 \\
\quad \text { found } 337.0847\end{array}$ & $\begin{array}{c}>250 \\
(\text { decomp.) }\end{array}$ \\
\hline $7 n$ & $\begin{array}{l}\text { DMSO: } 2.43(3 \mathrm{H}, \mathrm{s}), 2.48(3 \mathrm{H}, \mathrm{s}), 7.18(1 \mathrm{H}, \mathrm{dd} \\
J=8.4 \text { and } 0.9 \mathrm{~Hz}), 7.39(1 \mathrm{H}, \text { br s}), 7.48 \\
(1 \mathrm{H}, \mathrm{d}, J=8.4 \mathrm{~Hz}), 8.06(2 \mathrm{H}, \mathrm{d}, J=9.6 \mathrm{~Hz}) \\
8.13(2 \mathrm{H}, \mathrm{d}, J=9.6 \mathrm{~Hz})\end{array}$ & $\begin{array}{c}2426,1680.1618,1594,1520 \\
1490,1436,1377,1240 \\
1204,1111,1034 \mathrm{~cm}^{-1}\end{array}$ & $\begin{array}{l}\text { Calcd for } \mathrm{C}_{18} \mathrm{H}_{14} \mathrm{~N}_{5} \mathrm{O}_{3} \\
\quad\left([\mathrm{M}-\mathrm{H}]^{-}\right) 348.1102 \\
\quad \text { found } 348.1098\end{array}$ & $143-147$ \\
\hline 70 & $\begin{array}{l}\mathrm{CDCl} 3: 2.30(3 \mathrm{H}, \mathrm{s}), 2.36(3 \mathrm{H}, \mathrm{s}), 3.83(3 \mathrm{H}, \mathrm{s}), \\
6.97(1 \mathrm{H}, \mathrm{d}, J=7.8 \mathrm{~Hz}), 6.99(2 \mathrm{H}, \mathrm{d}, J=7.8 \mathrm{~Hz}), \\
7.12(1 \mathrm{H}, \mathrm{br} \mathrm{s}), 7.20(1 \mathrm{H}, \mathrm{d}, J=7.8 \mathrm{~Hz}), \\
7.58(2 \mathrm{H}, \mathrm{d}, J=7.8 \mathrm{~Hz}) .\end{array}$ & $\begin{array}{c}3046,2998,2948,2907,2834 \\
1655,1522,1440.1374,1245 \\
1132,1091,1022,1004 \mathrm{~cm}^{-1}\end{array}$ & $\begin{array}{c}\text { 4, } \\
\text { 5, } \\
1 \quad\left([\mathrm{M}+\mathrm{H}]^{+}\right) 335.1502 ; \\
\text { found } 335.1491\end{array}$ & $120-124$ \\
\hline $7 p$ & $\begin{array}{l}\mathrm{CDCl} 3: 2.39(3 \mathrm{H}, \mathrm{s}), 2.41(3 \mathrm{H}, \mathrm{s}), 7.04(1 \mathrm{H}, \mathrm{d}, \\
J=8.4 \mathrm{~Hz}), 7.10-7.35(2 \mathrm{H}, \text { broad }), 7.35(1 \mathrm{H}, \mathrm{t}, \\
J=7.6 \mathrm{~Hz}), 7.45(2 \mathrm{H}, \mathrm{dd}, J=8.0 \text { and } 7.6 \mathrm{~Hz}), \\
7.63(2 \mathrm{H}, \mathrm{d}, J=8.0 \mathrm{~Hz}), 7.66(2 \mathrm{H}, \mathrm{d}, J=7.6 \mathrm{~Hz}), \\
7.76(2 \mathrm{H}, \mathrm{d}, J=7.6 \mathrm{~Hz}) .\end{array}$ & $\begin{array}{c}3027,2952,2910.2867,1738 \\
1659,1529,1490.1431,1303 \\
1239,1031,1007 \mathrm{~cm}^{-1}\end{array}$ & $\begin{array}{c}\text { 8, Calcd for } \mathrm{C}_{24} \mathrm{H}_{19} \mathrm{~N}_{4} \mathrm{O} \\
3, \quad\left([\mathrm{M}-\mathrm{H}]^{-}\right) 379.1564 \\
\text { found } 379.1572 .\end{array}$ & $139-145$ \\
\hline
\end{tabular}

*DMSO: measured in DMSO- $\mathrm{d}_{6}, \mathrm{CDCl}_{3}$ : measured in $\mathrm{CDCl}_{3}$. 
Table II. Inhibition of prostate cancer antigen-1 (PCA-1) and DU145 cell growth, stability in S9 mixture after 10 min at $15^{\circ} \mathrm{C}$, and serum concentration at $60 \mathrm{~min}$ after oral administration of $32 \mathrm{mg} / \mathrm{kg}$ 2-(5-substituted benzimidazol-2-yl)-4,5-substituted-3-hydroxy-pyrazoles.

\begin{tabular}{|c|c|c|c|c|c|c|c|c|}
\hline \multirow[t]{2}{*}{ Compound } & \multicolumn{3}{|c|}{ Structure $^{\mathrm{a}}$} & \multirow[t]{2}{*}{$\begin{array}{l}\text { PCA-1 inhibition, } \\
\mathrm{IC}_{50}(\mu \mathrm{M})\end{array}$} & \multicolumn{2}{|c|}{$\begin{array}{l}\text { DU145 cell growth } \\
\text { inhibition }(\%)\end{array}$} & \multirow{2}{*}{$\begin{array}{l}\text { Remainder after } \\
\text { reaction with } \\
\text { S9 mixture }\end{array}$} & \multirow{2}{*}{$\begin{array}{l}\text { Concentration } \\
\text { in serum } \\
(\mu \mathrm{g} / \mathrm{ml})\end{array}$} \\
\hline & $\mathrm{R}^{1}$ & $\mathrm{R}^{2}$ & $\mathrm{R}^{3}$ & & At $1 \mu \mathrm{M}$ & At $10 \mu \mathrm{M}$ & & \\
\hline 1 (HUHS015) & $\mathrm{CH}_{3}$ & $\mathrm{CH}_{3}$ & $\mathrm{CH} 2 \mathrm{Ph}$ & 0.7 & 35 & 54 & $42 \%$ & 0.08 \\
\hline $7 \mathbf{a}$ & $\mathrm{Cl}$ & $\mathrm{CH}_{3}$ & $\mathrm{CH}_{2} \mathrm{Ph}$ & 4.5 & 24 & 36 & $81 \%$ & 0.15 \\
\hline $7 b$ & $\mathrm{CF}_{3}$ & $\mathrm{CH}_{3}$ & $\mathrm{CH}_{2} \mathrm{Ph}$ & 5.9 & 34 & 47 & $72 \%$ & 0.02 \\
\hline $7 c$ & $4-\mathrm{CH}_{3}-\mathrm{Ph}-$ & $\mathrm{CH}_{3}$ & $\mathrm{CH}_{2} \mathrm{Ph}$ & 12.0 & 78 & 61 & $64 \%$ & $\mathrm{ND}^{\mathrm{b}}$ \\
\hline $7 d$ & $\mathrm{CH}_{3}$ & $\mathrm{CH}_{3}$ & $\mathrm{Ph}$ & 9.7 & $\mathrm{NT}^{\mathrm{c}}$ & 32 & $74 \%$ & 2.45 \\
\hline $7 e$ & $\mathrm{CH}_{3}$ & $\mathrm{CH}_{3}$ & $\mathrm{COOH}$ & $>10(37 \%$ at $10 \mathrm{mM})$ & -20 & -11 & $87 \%$ & 0.22 \\
\hline $7 f$ & $\mathrm{CH}_{3}$ & $\mathrm{CH}_{3}$ & $\mathrm{CH}(\mathrm{Ph})_{2}$ & 7.2 & 52 & 72 & $85 \%$ & 0.17 \\
\hline $7 \mathrm{~g}$ & $\mathrm{Cl}$ & $\mathrm{Ph}$ & $\mathrm{Ph}$ & 6.9 & 31 & 38 & $76 \%$ & 1.03 \\
\hline $7 \mathrm{~h}$ & $\mathrm{CH}_{3}$ & $\mathrm{Ph}$ & $\mathrm{Ph}$ & $>10(49 \%$ at $10 \mathrm{mM})$ & 12 & 19 & $98 \%$ & 0.31 \\
\hline $7 \mathbf{i}$ & $\mathrm{CH}_{3}$ & $\mathrm{Ph}$ & $\mathrm{CH}_{3}$ & $>10(6 \%$ at $10 \mathrm{mM})$ & -6 & 27 & $35 \%$ & 0.33 \\
\hline
\end{tabular}

aSee Figure 3. bND: Not detected. cNT: Not tested.

water. Two microliters of each sample produced was then used as template in real-time polymerase chain reaction (PCR) using BioRad iQ SYBR Green Supermix to $20 \mu l$. The cycling conditions consisted of an initial single cycle at $95^{\circ} \mathrm{C}$ for $10 \mathrm{~s}$ followed by 40 cycles at $95^{\circ} \mathrm{C}$ for $5 \mathrm{~s}$, at $61^{\circ} \mathrm{C}$ for $30 \mathrm{~s}$, and at $72^{\circ} \mathrm{C}$ for $15 \mathrm{~s}$. The PCA-1-inhibitory effects of compounds were determined by quantitative analysis with real-time PCR.

Inhibitory effect of compounds on proliferation of DU145 cells. The experiments to examine the inhibitory effects of compounds with DU145 cells proliferation were carried out in a 96-well plate and the number of viable cells at the end of incubation was determined by 2-(4-iodophenyl)-3-(4-nitrophenyl)-5-(2,4-disulfophenyl)-2Htetrazolium, monosodium salt (WST) assay, which is determined by measuring the capacity of the cells to reduce WST to formazan. Briefly, $5 \times 10^{3}$ cells/well in $90 \mu \mathrm{l}$ culture medium were incubated in the presence or absence of each compound for $48 \mathrm{~h}$. After addition of $10 \mu \mathrm{l}$ of WST-1/1-methoxy-5-methylphenazinium methylsulfate solution, the plates were incubated at $37^{\circ} \mathrm{C}$ in a humidified atmosphere containing $5 \% \mathrm{CO}_{2}$ for $2 \mathrm{~h}$. Absorbance was then measured using a microplate reader with a test wavelength of 450 $\mathrm{nm}$ and a reference wavelength of $630 \mathrm{~nm}$. The percentage of inhibition by each compound was calculated, compared with $0.1 \%$ DMSO-treated control.

Measurement of compound stability in S9 mixture. The tested compound $(2 \mathrm{mg} / \mathrm{ml}$, reaction volume $1 \mathrm{ml})$ was added to a $\mathrm{S} 9$ mixture with co-factors (\#S9MIX; IEDA Co., Ltd., Tokyo, Japan) for $10 \mathrm{~min}$ at $15^{\circ} \mathrm{C}$ or $0^{\circ} \mathrm{C}$ as control (7). After washing with nhexane, the target compounds were twice extracted with ethyl acetate. After removal of solvents by a speed-vac apparatus (KOIKE Precision Instruments Co., Ltd., Itami, Japan), the amount of compound was then determined using an HPLC system (\#8020; TOSOH Co., Ltd., Tokyo, Japan) with YMC-Pack Pro C18 (YMC Co., Ltd., Kyoto, Japan) at $1.0 \mathrm{ml} / \mathrm{min}$ of $0.1 \% \mathrm{TFA} / \mathrm{H}_{2} \mathrm{O}$ as mobile phase A, $0.1 \% \mathrm{TFA} / \mathrm{CH}_{3} \mathrm{CN}$ as mobile phase $\mathrm{B}$. The amount of the compound remaining in the $\mathrm{S} 9$ mix was determined compared with the control.
Measurement of serum concentration of compounds in rats after oral administration. Male SD rats were fasted for $18 \mathrm{~h}$ then 10 or $32 \mathrm{mg} / \mathrm{kg}$ of compound was suspended in $0.5 \%$ methylcellulose (MC) and orally administered. At 30 or 60 min after administration, blood samples were obtained from abdominal vein or subclavian vein under anesthesia and centrifuged, the serum was separated and stored at $-20^{\circ} \mathrm{C}$. The concentration of each compound in the serum was measured using HPLC as mentioned above.

Growth-inhibitory effect in mice bearing DU145 xenograft. Male nude mice were implanted subcutaneously with approximately $8 \times 10^{6}$ DU145 cells mixed with BD Matrigel ${ }^{\mathrm{TM}}$ Basement Membrane Matrix High Concentration (BD Biosciences Bedford, MA, USA) into the right flank. When the estimated tumor volume had reached almost $200 \mathrm{~mm}^{3}$, after randomization into two treatment groups, HUHS015 or vehicle (50\% DMSO, $15 \% \mathrm{EtOH}, 35 \%$ sterile water) was subcutaneously administered once a day for 28 days.

Next, male nude mice were implanted subcutaneously with approximately $8 \times 10^{6}$ DU145 cells mixed with BD Matrigel $^{\mathrm{TM}}$ Basement Membrane Matrix High Concentration into the right flank. When the estimated tumor volume had reached almost 200 $\mathrm{mm}^{3}$, tumors were cut to $\sim 10 \mathrm{~mm}^{3}$ blocks and were then implanted subcutaneously into the right flank of another nude mouse of $\mathrm{BALB} / \mathrm{c}$ background. When the estimated tumor volume in the mice had reached 100 to $300 \mathrm{~mm}^{3}$, animals were divided into three experimental groups of six mice and treated subcutaneously with docetaxel $(2.5 \mathrm{mg} / \mathrm{kg}$, once a week) or compound $71(10 \mathrm{mg} / \mathrm{kg}$, once a day) suspended in $0.5 \%$ MC for 25 days, all mice were equally administered $0.5 \% \mathrm{MC}$ as vehicle. The tumor volume was calculated every 2 or 3 days using the following formula: tumor volume $\left(\mathrm{mm}^{3}\right)=L \times W^{2} / 2$, where $L$ and $W$ represent the length and the width of the tumor mass, respectively. The changes of tumor volume before administration were calculated. The day after last administration, blood samples were obtained from an abdominal vein under anesthesia and centrifuged, the serum was separated and stored at $-20^{\circ} \mathrm{C}$. Serum concentrations of glutamic oxaloacetic transaminase (GOT), glutamic pyruvate transaminase (GPT), creatinine, and blood urea nitrogen (BUN) were measured (WAKO 


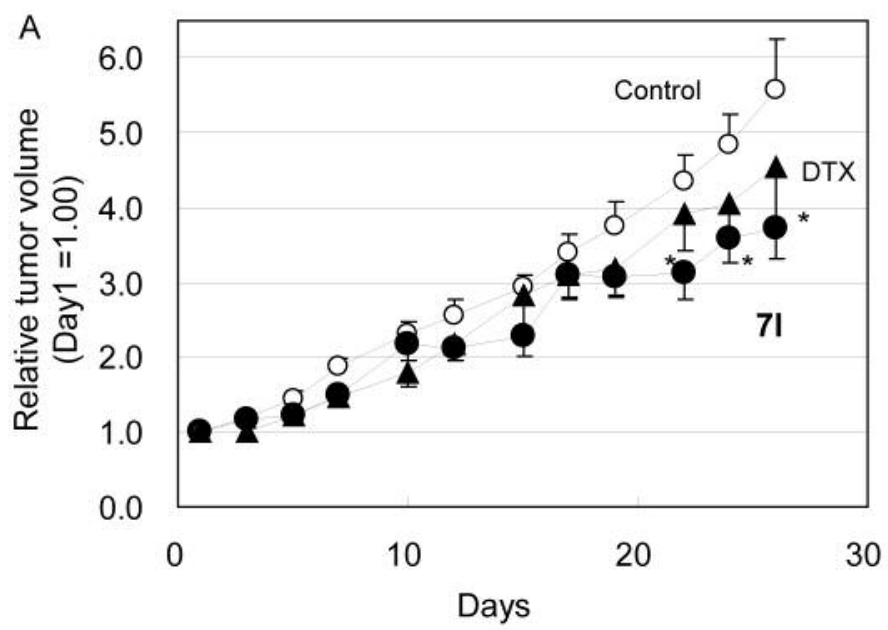

B

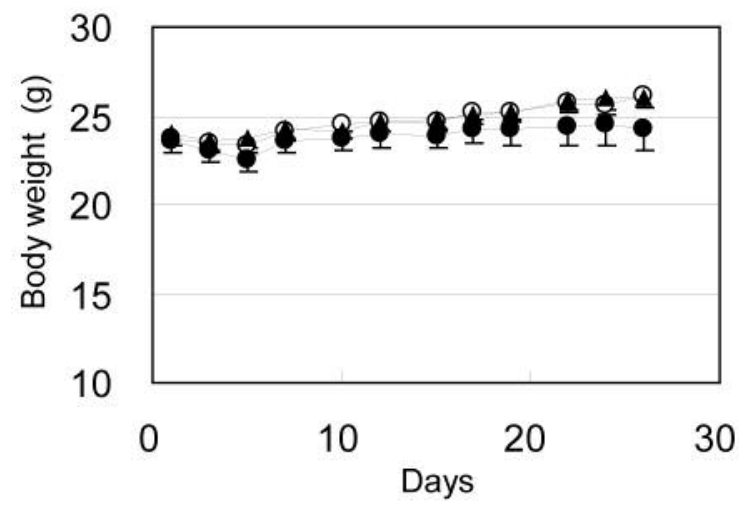

C

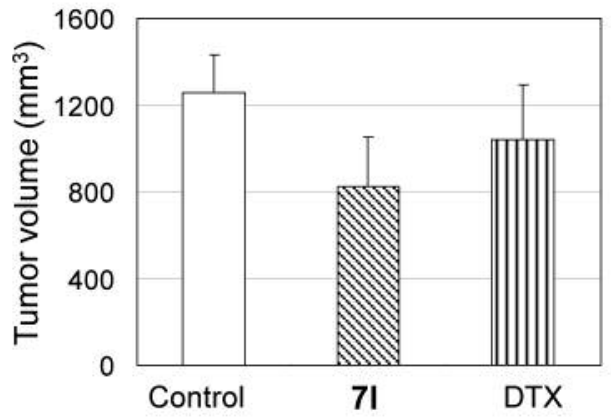

Figure 4. The effects of compound $7 l$ [10 mg/kg, subcutaneously (s.c.), once a day] and docetacel (DTX, $2.5 \mathrm{mg} / \mathrm{kg}$, s.c., once a week) on body weights and tumor in mice bearing DU145 cell xenografts. After randomization into three groups, mice were administered DTX, $7 l$, or vehicle alone was administered s.c. once a week, or once a day, respectively. A: Tumor volume was calculated by caliper measurements of the width (W) and length $(L)$ (volume $\left.=L \times W^{2} / 2\right)$, and tumor volumes were estimated relative to those at day 1. B: Body weights were measured at intervals. $C$ : Tumor volumes $\left(\mathrm{mm}^{3}\right)$ were measured on the final day. Each value represents the mean \pm SE of six mice. *Significantly different at $p<0.05$ in comparison with the vehicle-treated control by Student's t-test.

Table III. Inhibition of prostate cancer antigen-1 (PCA-1) and DU145 cell growth, stability in S9 mixture after 10 min at $15^{\circ} \mathrm{C}$, and serum concentration after oral administration of $10 \mathrm{mg} / \mathrm{kg}$ 2-(5-substituted- benzimidazol-2-yl)-4-substituted-3-hydroxy-5-methyl-pyrazoles.

\begin{tabular}{|c|c|c|c|c|c|c|c|c|}
\hline \multirow[t]{2}{*}{ Compound } & \multirow[b]{2}{*}{$\mathrm{R}^{1}$} & \multicolumn{2}{|c|}{ Structure ${ }^{a}$} & \multirow[t]{2}{*}{$\begin{array}{l}\text { PCA-1 inhibition, } \\
\mathrm{IC}_{50}(\mu \mathrm{M})\end{array}$} & \multicolumn{2}{|c|}{$\begin{array}{l}\text { DU145 cell growth } \\
\text { inhibition }(\%)\end{array}$} & \multicolumn{2}{|c|}{$\begin{array}{l}\text { Concentration in serum } \\
(\mu \mathrm{g} / \mathrm{ml}) \text { after oral } \\
\text { administration }\end{array}$} \\
\hline & & $\mathrm{R}^{2}$ & $\mathrm{R}^{3}$ & & At $1 \mu \mathrm{M}$ & At $10 \mu \mathrm{M}$ & $30 \mathrm{~min}$ & $60 \mathrm{~min}$ \\
\hline $7 \mathbf{j}$ & $\mathrm{CF}_{3}$ & $\mathrm{CH}_{3}$ & $\mathrm{Ph}$ & 1.6 & 60 & 78 & 1.00 & 0.33 \\
\hline $7 k$ & $\mathrm{CH}_{3} \mathrm{O}$ & $\mathrm{CH}_{3}$ & $\mathrm{Ph}$ & 1.0 & 65 & 78 & 0.63 & 0.18 \\
\hline 71 & $\mathrm{~F}$ & $\mathrm{CH}_{3}$ & $\mathrm{Ph}$ & 2.9 & 63 & 77 & 1.02 & 0.73 \\
\hline $7 \mathrm{~m}$ & $\mathrm{CH} 3$ & $\mathrm{CH}_{3}$ & 4-ClPh & $>10(33 \%$ at $10 \mu \mathrm{M})$ & $\mathrm{NT}^{\mathrm{b}}$ & & NT & \\
\hline $7 n$ & $\mathrm{CH} 3$ & $\mathrm{CH}_{3}$ & 4-NO2Ph & $>10(39 \%$ at $10 \mu \mathrm{M})$ & NT & & NT & \\
\hline 70 & $\mathrm{CH} 3$ & $\mathrm{CH}_{3}$ & 4-CH3OPh & $>10(18 \%$ at $10 \mu \mathrm{M})$ & NT & & NT & \\
\hline $7 p$ & $\mathrm{CH} 3$ & $\mathrm{CH}_{3}$ & 4-Ph-Ph & $>10(11 \%$ at $10 \mu \mathrm{M})$ & NT & & NT & \\
\hline
\end{tabular}

aSee Figure 3. bNT: not tested. 
A

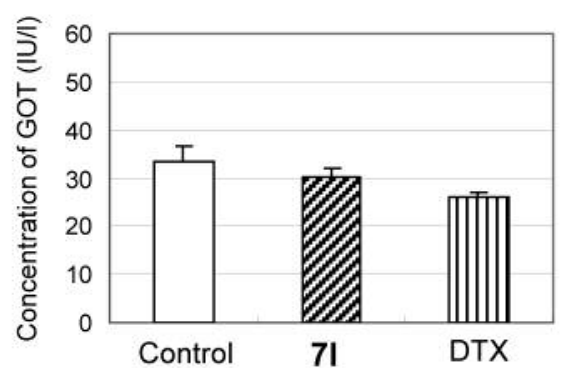

C

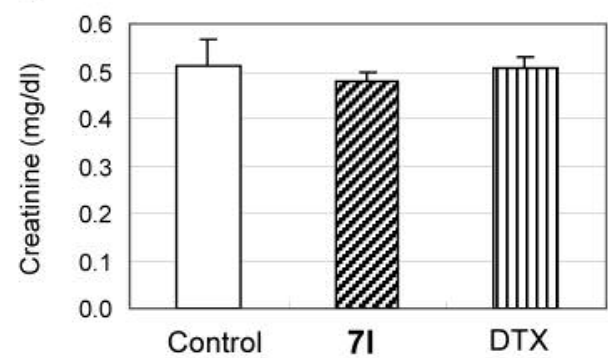

B

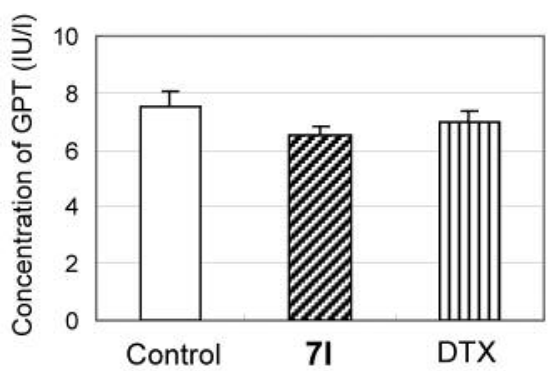

D

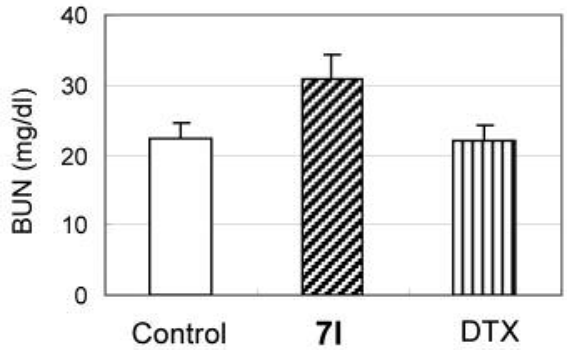

Figure 5. Serum glutamic oxaloacetic transaminase (GOT), glutamic pyruvate transaminase (GPT), creatinine, and blood urea nitrogen (BUN) of mice were measured on the final day. The values represent means \pm SE $(n=6)$. No statistical significance was observed by Student's $t$-test.

Pure Chemical Industries, Ltd. Chuo-ku, Osaka, Japan). Results are shown as means $\pm \mathrm{SE}$ of six mice and statistical significance of differences were analyzed by $t$-test.

\section{Results and Discussion}

We evaluated the stability of compounds studied in this work and estimated their anti-PCA-1/ALKBH3 and anti-DU145 cell growth activities in vitro (Tables II and III).

Replacement of the methyl at the 5-position of the benzimidazole ring ( $\mathrm{R} 1)$ with $\mathrm{Cl}(\mathbf{7 a})$ produced almost 2-fold increase in stability in the S9 mixture treatment (1: $42 \%$ vs. 7a: $81 \%$ remaining, Table II), and a higher serum concentration $(0.15 \mu \mathrm{g} / \mathrm{ml})$ compared to those of $\mathbf{1}(0.08 \mu \mathrm{g} / \mathrm{ml})$, while antiPCA-1/ALKBH3 activity was reduced [half maximal inhibitory concentration $\left.\left(\mathrm{IC}_{50}\right)=0.7 v s .4 .5 \mu \mathrm{M}\right]$, indicating that the methyl was metabolized in the liver and that modifications which yielded derivatives with resistance to metabolic reactions in the S9 mixture would be effective for enhancement of in vivo activities.

Replacement of the methyl with trifluoromethyl (7b) and 4-Me-phenyl (7c) also afforded stable derivatives in the S9 mixture treatment (Table II), while anti-PCA-1/ALKBH3 and anti-DU145 growth activities were reduced. Compound 7c was, curiously, not detected in serum, while it was relatively stable in the $\mathrm{S} 9$ mixture. We speculate that this result was due to the low solubility of 7c (data not shown) and that 7c might be precipitated in gastrointestinal tract after oral administration.

Replacement of the benzyl with a carboxylate (7e) resulted in good serum concentration $(0.22 \mu \mathrm{g} / \mathrm{ml}, 60 \mathrm{~min}$ after oral administration), but showed only weak inhibitory activities on PCA-1/ALKBH3 and growth of DU145 cells. Derivatives bearing phenyl rings (7d, 7g-7h) or a diphenylmethyl (7f) instead of a benzyl at the 4 position of the pyrazole were then synthesized because such benzyl moieties are often metabolized (Figure 1). Compounds $\mathbf{7 d}$ and $\mathbf{7 g}$ demonstrated good stability in the $\mathrm{S} 9$ mixture and good serum concentrations after oral administration $(2.45 \mu \mathrm{g} / \mathrm{ml}$ and $1.03 \mu \mathrm{g} / \mathrm{ml}$, respectively), which were more than 10 times higher than those of 1 (Table II). Based on these results, we fixed the phenyl at the 4 position of the pyrazole for further studies because such stability in the $\mathrm{S} 9$ mixture and good bioavailability properties were attractive.

Replacement of the methyl group of the benzimidazole in 7d, which could be as easily metabolized by the liver as the methyl group of $\mathbf{1}$, with putatively metabolically stable groups, trifluoromethyl (7j), methoxy (7k), and fluoro atom (7l), was carried out. Derivatives $\mathbf{7 d}, \mathbf{7 j}$, and $\mathbf{7 l}$ exhibited serum concentrations of 1.00 .0 .63 , and $1.02 \mu \mathrm{g} / \mathrm{ml}$ at $30 \mathrm{~min}$ after oral administration at $10 \mathrm{mg} / \mathrm{kg}$, respectively, in line with our expectations (Table III). Moreover, compounds $7 \mathbf{k}$ and $\mathbf{7 l}$ 
exhibited more potent anti-growth activities compared to that of $\mathbf{1}$, while their anti-enzymatic inhibitory activities were weaker than that of $\mathbf{1}$. We thought this discordance between the enzyme assay and cell-based assay was due to differences in their membrane-permeability. Introductions of substitutions on the phenyl ring (7m-7p) produced disappointing inhibition of anti-PCA-1/ALKBH3 (Table III). Among this series, we selected compound $\mathbf{7 l}$ for further studies because it exhibited the highest serum concentration both at $30 \mathrm{~min}$ and $60 \mathrm{~min}$ after oral administration $(10 \mathrm{mg} / \mathrm{kg})$ and adequate inhibitory activities both in enzymatic $\left(\mathrm{IC}_{50}=2.9 \mu \mathrm{M}\right)$ and DU145 assays (63\% inhibition at $1 \mu \mathrm{M})$. The serum concentration of 71 was almost 10 times higher than that of HUHS015 (1) at $60 \mathrm{~min}$ after oral administration $(10 \mathrm{mg} / \mathrm{kg})$, and its anti-growth effects on DU145 were slightly more potent than those of 1 , while its PCA-1/ALKBH3 inhibitory activity was weaker than that of $\mathbf{1}$.

The growth inhibition by compound 71 in the xenograft model bearing DU145 tumors was examined for 26 days (10 $\mathrm{mg} / \mathrm{kg}, s . c$.) and compared to the inhibition exerted by docetaxel at approximately its clinical dosage (8) $(2.5 \mathrm{mg} / \mathrm{kg}$, s.c., Figure 4). Compound 71 demonstrated potent growthinhibitory activity compared to docetaxel without limiting weight gain, even after 26 days of continuous administration. The inhibitory activity of compound 71 was more potent than that of 1. Docetaxel administration at $2.5 \mathrm{mg} / \mathrm{kg}$ was a critical dose in the DU145-bearing xenograft model because continuous administration at this dose caused edema-like side-effects (9) that are often observed in clinical use. Serum concentrations of GOT, GPT, creatinine, and BUN were measured on the final day (Figure 5), and there were no obviously irregular values, indicating a low toxicity of compound $\mathbf{7 l}$.

\section{Conclusion}

We designed and synthesized metabolically stable HUHS015 derivatives and evaluated their stabilities in S9 mixture and their serum concentrations after oral administration because HUHS015 is easily metabolized and decomposed in vivo. We also estimated the anti-PCA-1 and anti-growth activities of these derivatives in vitro to obtain potent novel PCA1/ALKBH3 inhibitors in vivo. As a result of modifications to $\mathbf{1}$, replacements to two metabolically susceptive moieties, the methyl group at the 5 position of benzimidazole and the benzyl of $\mathbf{1}$, to the more stable fluoro atom and phenyl group in compound 7l were effective both in improving the stabilization in S9 mixture and in achieving a high serum concentration after oral administration. Compound $7 \mathbf{l}$ exhibited potent inhibitory activities against DU145 tumors in a xenograft model without observable side-effects after subcutaneous administration for 26 days, as expected. Currently, further modifications of compound $7 \mathbf{l}$ and other derivatives to obtain a clinical trial compound are in progress. Additionally, the effects of combination treatment with PCA-1/ALKBH3 inhibitors and prostate cancer drugs mainly used in clinic, such as docetaxel, are also in progress and will be reported in the near future.

\section{Acknowledgements}

This research was supported in part by JSPS KAKENHI Grant Numbers 26460164 and $15 \mathrm{~K} 08036$ and by the Japan Agency for Medical Research and Development.

\section{References}

1 DeFrancesco L: Prostate cancer prevention trial launched. Nat Medicine 7: 1076, 2001.

2 Konishi N, Nakamura M, Ishida E, Shimada K, Mitsui E, Yoshikawa R, Yamamoto $\mathrm{H}$ and Tsujikawa K: High expression of a new marker PCA-1 in human prostate carcinoma. Clin Cancer Res 11: 5090-5097, 2005.

3 Shimada K, Nakamura M, Ishida E, Higuchi T, Yamamoto H, Tsujikawa $\mathrm{K}$ and Konishi N: Prostate cancer antigen-1 contributes to cell survival and invasion though discoidin receptor 1 in human prostate cancer. Cancer Sci 99: 39-45, 2008.

4 Koike K, Ueda Y, Hase H, Kitae K, Fusamae Y, Masai S, Inagaki T, Saigo Y, Hirasawa S, Nakajima K, Ohshio I, Makino Y, Konishi N, Yamamoto H and Tsujikawa K: Anti-tumor effect of $A l k B$ homolog 3 knockdown in hormone- independent prostate cancer cells. Curr Cancer Drug Targets 12: 847-856, 2012.

5 Dango S, Mosammaparast N, Sowa ME, Xiong LJ, Wu F, Park K, Rubin M, Gygi S, Harper JW and Shi Y: DNA unwinding by ASCC3 helicase is coupled to ALKBH3-dependent DNA alkylation repair and cancer cell proliferation. Mol Cell 44: 373384, 2011.

6 Nakao S, Mabuchi M, Shimizu T, Itoh Y, Takeuchi Y, Ueda M, Mizuno H, Shigi N, Ohshio I, Jinguji K, Ueda Y, Yamamoto M, Furukawa T, Aoki S, Tsujikawa $\mathrm{K}$ and Tanaka A: Design and synthesis of prostate cancer antigen-1 (PCA-1/ALKBH3) inhibitors as anti-prostate cancer drugs. Bioor Med Chem Lett 24: 1071-1074, 2014.

7 Japanese website for S9 mixture: http://www.ieda.co.jp/boeki/ products/ detail381.html.

8 A Japanese official PMDA website. http://www.info.pmda.go.jp/ go/interview/1/780069_4240405A1037_1_011_1F, and Sanofi website for docetaxel(http://pk.sanofi-aventis.com/products/ Taxotere-New.pdf).

9 Mabuchi M, Ueda M, Yoshida Y, Horiike K, Yamaoka K, Nakao S, Shimizu T, Ueda Y, Tsujikawa K and Tanaka A: Systematic trial for evaluating docetaxel in a human prostate cancer cell DU145 xenograft model. Anticancer Res 34: 1665-1676, 2017.

Received October 5, 2017

Revised October 31, 2017 Accepted November 2, 2017 